\title{
ESCOLAS INDÍGENAS. CONTEXTOS, PERCEPÇÕES E DESAFIOS INTERCULTURAIS
}

\section{Indigenous schools. Intercultural contexts, perceptions and challenges}

\author{
Adecir Pozzen ${ }^{1}$ \\ Secretaria de Estado da Educação de Santa Catarina (SED/sC/Brasil) \\ Correo-e: pozzeradecir@hotmail.com \\ Elcio CecchetTi ${ }^{2}$ \\ Universidade Comunitária da Região de Chapecó (UNOCHAPECÓ/Brasil) \\ Correo-e: elcio.educ@hotmail.com \\ Recibido: I2 de octubre de 2019 \\ Envío a informantes: Is de octubre de 2019 \\ Aceptación definitiva: is de abril de 2020
}

Resumo: O artigo trata da escola indígena no Brasil, seus princípios, objetivos, organização e desafios contemporâneos. Reflete criticamente os aspectos relativos as condições e possibilidades da formação cultural e técnico-profissional dos alunos indígenas, bem como a dimensão epistêmico-metodológica que fundamenta a educação escolar indígena intercultural. Trata-se de uma abordagem qualitativa, cuja metodologia adotada é bibliográfica e documental. Ao analisar os parcos avanços ocorridos nas últimas décadas e os inúmeros desafios ainda existentes, conclui-se que a educação escolar indígena

I Doutor e Mestre em Educação pela Universidade Federal de Santa Catarina (UFSC). Realizou doutorado sanduíche na Universidade de Salamanca (USAL), entre ago. 2018 e jun. 2019 (Apoio CAPEs/Brasil - Código de Financiamento oor). Técnico-pedagógico da Secretaria de Estado da Educação de Santa Catarina. Membro pesquisador dos Grupos de Pesquisa «Hermenêuticas da Cultural, Mundo e Educação» (PPGE/ UFSC), «Ethos, Alteridade e Desenvolvimento» (GPEAD/Furb) e «SUR Paidéia» (Univ. de la República del Uruguay).

2 Doutor e Mestre em Educação pela Universidade Federal de Santa Catarina (UFSc). Docente do Mestrado em Educação e Coordenador do Curso Ciências da Religião da Universidade Comunitária da Região de Chapecó (unochapecó). Vice-líder do Grupo de Pesquisa Ethos, Alteridade e Desenvolvimento (GPEAd/Furb) e do Grupo de Pesquisa Desigualdades Sociais, Diversidades Socioculturais e Práticas Educativas (UNOCHAPECó). 
carece de maior autonomia e investimento estatal, de modo que, gradativamente, as próprias comunidades indígenas possam fazer a gestão de suas unidades escolares. Mesmo diante de inúmeras dificuldades, as experiências de educação escolar indígena intercultural tem proporcionado maior reconhecimento, valorização e respeito ao pensamento, formas de vida e ciências produzidas no interior das comunidades indígenas, mesmo elas estando às margens dos sistemas culturais, econômicos e políticos hegemônicos.

Palavras Chave: educação; escolas indígenas; interculturalidade.

АвsтRAст: The article deals with the indigenous school in Brazil, its principles, objectives, organization and contemporary challenges. Reflect critically on aspects related to the conditions and possibilities of cultural and technical training of indigenous students, as well as the epistemic-methodological dimension that underpins intercultural indigenous school education. It is a qualitative reflection, whose adopted methodology is bibliographic and documentary. By analyzing the few advances that have been made in recent decades and the many challenges that remain, it can be concluded that indigenous school education lacks greater autonomy and state investment, so that indigenous communities themselves can gradually manage their school units. Even in the face of numerous difficulties, the experiences of intercultural indigenous school education have provided greater recognition, appreciation and respect for thought, life forms and sciences produced within indigenous communities, even though they are on the margins of hegemonic cultural, economic and political systems.

KEY WORDs: education; indigenous schools; interculturality.

\section{Introdução}

Tratar de educação escolar indígena no Brasil, um país continental, culturalmente diverso, marcado por desigualdades sociais sustentadas por uma elite econômica que historicamente se opõe ao conjunto de direitos sociais das minorias e da classe trabalhadora, constitui-se em um exercício desafiador. Porém, essa ação é necessária ao desenvolvimento de uma consciência político-social-educativa, correlata a concepção de educação enquanto direito inalienável de todo ser humano, independentemente de origem, gênero, crença ou condição social. É em um cenário de contradições que se situam as iniciativas de educação escolar indígena no Brasil, muito similar à de outros países latino-americanos e caribenhos.

No interior das comunidades indígenas brasileiras, desde o início do século XVI, com o processo de colonização, a educação foi um instrumento ideológico a serviço da catequização e integração forçada dos indígenas à sociedade nacional. Esse processo iniciou com os missionários jesuítas, chegando até o Serviço de Proteção aos Índios (SPI), criado em I9ıo. O que caracteriza esse período é a negação da diferença, a aculturação e a conversão do indígena em pessoa «civilizada», já que era considerado «selvagem», «irracional», «sem alma». Neste contexto, a educação escolar foi estratégica na imposição cultural de valores, epistemes e práticas que negavam identidades, linguagens, espiritualidades e saberes indígenas (Brasil, I998).

De acordo com Ferreira (1992), essa foi a primeira fase da educação escolar indígena no Brasil. A etapa posterior compreende o período entre a criação do sPI até a instituição do Fundação Nacional do Índio (FunAI), em 1967. Trata-se de um momento 
em que, apesar da continuidade dos ataques e dizimações aos povos indígenas, houve maior interesse em compreender a diversidade linguística e cultural dos autóctones, embora essa compreensão estivesse associada ao processo de sua integração na produção de bens de interesse nacional e comercial.

Uma terceira etapa tem início nos anos 70, com o ingresso de organizações não governamentais (ONGs) no cenário nacional, cujo interesse expresso era a defesa das causas indigenistas, provocando uma maior visibilidade de suas pautas através de assembleias e articulação de lideranças, sendo a educação escolar indígena uma das principais reivindicações.

Por conseguinte, uma quarta fase se concretiza nos anos 80, a partir de lutas em torno da reestruturação da política indigenista do Estado brasileiro. Assumida por inúmeras lideranças indígenas e apoiada por ONGs, houve uma das maiores articulações das populações indígenas da história em torno de pautas comuns, que resultaram na incorporação de vários direitos na Constituição Federal de i998. No que tange a educação, a Constituição assegurou que o ensino nas comunidades indígenas utilizará suas línguas maternas e incorporará seus processos próprios de aprendizagem.

Passados 30 anos destas conquistas, a atual conjuntura sóciopolítica do país parece estar caracterizando uma quinta fase: a do questionamento e enfraquecimento das políticas e direitos indigenistas em geral, o que, por consequência, afeta diretamente a educação escolar indígena.

As escolas indígenas são uma instituição recente nas políticas educacionais brasileiras, e ainda carecem de maior autonomia e reconhecimento no âmbito dos sistemas de ensino municipais, estaduais e federal. Os parcos avanços obtidos foram significativos, pois fortaleceram projetos e iniciativas de inclusão da população indígena em diferentes níveis de ensino, assim como contribuíram para o reconhecimento da escola indígena como um espaço de valorização, respeito e reconhecimento das culturas, línguas, crenças, saberes e epistemologias destes grupos.

Ao longo da história, antes mesmo da criação dos sistemas de ensino formais no Brasil, as populações indígenas, cada qual a seu modo, possuíam complexos sistemas de pensamento e modos próprios de produção, expressão, transmissãoe reelaboração dos saberes e concepções de mundo, humano e sobrenatural (Freire, 2004). Cada grupo produziu conhecimentos peculiares e desenvolveu um acervo de informações e reflexões sobre a natureza, a vida social, a existência humana e a de outros seres, constituindo o que podemos denominar de uma perspectiva epistêmico-filosófica indígena, tal como apresenta Mejía Huamán (2010, 20II, 20I8).

A atitude interpretativa e reflexiva diante do mundo e da vida, bem como a íntima relação com as forças e elementos naturais que caracterizam as concepções autóctones, permitem pensar a escola indígena enquanto possibilidade e espaço privilegiado de conhecimento e diálogo com outras tradições educativas, priorizando as concepções e cosmovisões indígenas na organização sociocultural, política, econômica e religiosa de cada povo.

Considerando esses aspectos, assim como a história e os fundamentos legais da educação brasileira, este trabalho objetiva refletir sobre a dimensão epistêmico-metodológico da escola indígena intercultural, ou seja, o que caracteriza a sua singularidade, pois, o adjetivo «indígena» introduz uma especificidade na concepção e no «ser» dessa escola.

Neste intento, apresentaremos alguns elementos relacionados a realidade das escolas indígenas no Brasil, a partir de experiências concretas realizadas em diferentes 
regiões do país. A partir dessas experiências, procuraremos refletir criticamente sobre aspectos relativos as condições e possibilidades da oferta da educação básica a estudantes indígenas. Ao mesmo tempo, apontaremos algumas situações que tornam esta modalidade de ensino uma experiência ainda fragmentada e descontínua, resultado de desarticulações entre os poderes constituídos e, ao mesmo tempo, da complexidade inerente a um projeto que procura assegurar o princípio da diversidade enquanto diferencial da escola intercultural indígena.

\section{Dimensão epistêmico-metodológica da educação indígena}

O caráter singular da escola indígena deriva dos pressupostos teórico-metodológicos pelos quais este modelo de educação procura se orientar, instaurando processos de decolonialidade do saber $^{3}$ e afirmando o paradigma da interculturalidade 4 . Há que se considerar, no entanto, que se de um lado ampliam-se as escolas indígenas, por outro, intensificam-se o risco de perda de elementos próprios da cosmologia e culturas indígenas, pois a própria noção de «escola» é um constructo histórico da cultura europeia-ocidental, que tende a privilegiar uma única forma de saber ao passo que colonializa e deslegitima as demais epistemologias existentes (Méndez, 2009).

Esse paradoxo fica evidente na voz de um professor indígena, quando ele constata que a escola tem violentado os conhecimentos e a organização da vida indígena, pois, em muitos casos, são submetidas às lógicas de normatização e exploração, contrários aos princípios das populações autóctones. Diz o referido professor:

A sociedade não percebe que a natureza está falando? As pessoas que residem neste ambiente precisam lutar para clamar aos poderes públicos, executivo, legislativo e judiciário que não desmatem as florestas e os biomas do cerrado. São fontes de nossas vidas no presente e no futuro, independentemente de classe baixa ou alta. Diante dessa crise de conhecimento e capitalismo global, enquanto liderança indígena, professor, estou preocupado com os jovens em nível de seu conhecimento histórico e cultural (Apinajé, 2017: 75).

Nas últimas décadas, um crescente número de intelectuais como Castro-Gómez (2007, 20II), Grosfoguel (2016), Mignolo (20IO, 20I3, 2017), Palermo (2009) e Walsh (20I3, 20I4), entre outros, vem denunciando a «colonialidade do saber» que recai sobre as esferas do conhecimento e seus campos de incidência, tais como escolas e universidades. Estes pensadores aludem que as lógicas de dominação colonial não foram superadas com a independência política das regiões conquistadas, pois a colonialidade mantemse por uma série de sistemas, estruturas, hierarquias, pedagogias e metodologias. Daí adveio, no intento de superação e resistência à esta condição, o projeto da «descolonialidade do saber». Particularmente, WALSH (20I3: 4) tem trabalhado com o termo «decolonialidade do saber», motivada pela compreensão de que não existe um estado nulo de colonialidade, mas sim posturas, posicionamentos, horizontes e projetos de «resistir, transgredir, intervir, insurgir, criar e incidir». O decolonial expressa, então, o caminho de luta contínua para criar «lugares de exterioridade e construções alter-(n)ativas» (p. 4).

4 Em conformidade com FORNET-BETANCOURT (200I), compreendemos interculturalidade como um «projeto político alternativo» que visa à reorganização das relações vigentes para superar as assimetrias de poder existentes entre os grupos socioculturais, e como um «projeto cultural compartilhado» que busca recriar as culturas a partir da vivência concreta do princípio de reconhecimento recíproco. Em consequência, o «intercultural» desponta como um espaço que se vai criando mediante o diálogo e comunicação entre as culturas e que vai edificando uma tomada de posição ética a favor da convivência com as diferenças. 
Este depoimento nos remete a um dos princípios elementares da cosmovisão indígena, muito difundida no contexto dos povos andinos', Pacha Mama (Mãe Natureza). De acordo com Huamán (20I8), pacha (natureza) não possui relevância apenas do ponto de vista filosófico, mas também econômico, político, ético e moral. Representa tempo, espaço, natureza e mundo onde todos os filhos retiram o seu sustento e encontram sentido à existência.

A instrumentalização da natureza pelo sistema-mundo europeu-capitalista, visando a mera exploração de seus recursos possui sérios limites. Ela não é uma fonte inesgotável. Daí a relevância das concepções e formas de conviver outras constituírem um eixo articulador da educação escolar indígena, já que são testemunho de que é possível viver em comunhão com a Pacha Mama.

Outra dimensão que caracteriza os fundamentos da educação indígena é a relacionalidade do todo (Estermann, 2006). Diferentemente do entendimento do pensamento ocidental, os povos indígenas enfatizam a existência de uma rede de nexos e vínculos que expressa a força vital de tudo o que existe. Deste modo, o indivíduo como tal praticamente «não existe» (não-ente). Seria algo perdido, ilhado da comunidade e des-relacionado. É como se estivesse morto (Estermann, 2006), o que justifica a forte ênfase na dimensão da coletividade.

De acordo com o mesmo autor, outro aspecto que caracteriza uma perspectiva epistemológica e metodológica é uma racionalidade não-racionalista. A razão (ratio) ocidental foi considerada a mais adequada para «ver» a realidade tal como ela é, bem como para «captá-la» através da elaboração conceitual, modo considerado mais autêntico para acessar o conhecimento. Desde uma perspectiva indígena, a razão opera como «auxiliar» das demais capacidades não-racionais (que não são «irracionais»), como os sentimentos, as emoções, até relações cognitivas "parapsicológicas» (pressentimentos, aspectos psicossomáticos, comunicação «telepática»), dentre outros. $\mathrm{O}$ indígena procura sentir a realidade, muito mais que conhecê-la, pensá-la e enquadrá-la em um conceito.

Considerando esses elementos é possível reconhecer que a educação escolar indígena tem muito a contribuir para a manutenção e fomento de projetos alternativos de formação humana, bem como para a decolonialidade do ser, pensar, saber e viver, pois trata-se de uma educação capaz de confrontar os projetos que se autoproclamam como universais, ainda tão presentes em políticas educacionais escolarizantes de nosso continente.

\section{Escolas indígenas no Brasil: princípios, objetivos, organização e desafios}

Não são poucos os registros históricos que reconhecem o legado de Francisco de Vitoria (I483-1546), assim como de Bartolomé de Las Casas (I484-1566) e Frei António de Montesinos (I475-1540), dentre outros, como precursores no reconhecimento da dignidade dos povos indígenas latino-americanos. Tal contribuição influenciou na criação do direito internacional moderno e na afirmação dos direitos humanos na América, mesmo que tardiamente, incluindo o direito à educação ${ }^{6}$.

Destacamos aqui os estudos de Mario Mejía Huamán (20II, 20I8) e de Josef Estermann (2006), dentre outros.

6 Conferir a análise de KraUSE (20I9) sobre a posição de Francisco de Vitoria ao apresentar a doutrina original de defesa dos direitos fundamentais dos povos indígenas. 
$\mathrm{Na}$ medida em que tomam conhecimento dos povos autóctones e das violências cometidas contra eles desde o início da Conquista, passam a refutar a ideia aristotélica de estado de escravidão natural, ou seja, «[...] na realidade, não são dementes, mas a seu modo têm uso da razão» (Vitória, 2006: 56). No entanto, esse reconhecimento dos indígenas como humanos não ocorreu na sua totalidade, pois, por exemplo, na obra De Indis (1532), Francisco de Vitória faz referência a eles como povos «bárbaros»». Essa definição classifica hierarquicamente o indígena como inferior e subalterno culturalmente. Há uma transposição da inferioridade do plano da natureza para o plano cultural. Em linhas gerais, pode-se afirmar que é sobre esta perspectiva que a educação indígena se orienta por quase quinhentos anos, tendo como eixos norteadores a moral judaico-cristã, o domínio e exploração da natureza e da mão de obra humana.

$\mathrm{O}$ modelo de educação imposto aos indígenas durante séculos passou a ser confrontado a partir da Declaração Universal dos Direitos Humanos (1948) e dos ideais de autodeterminação dos povos que, no contexto da Organização das Nações Unidas (ONU), desencadeou uma série de ações que resultaram na criação de um Grupo de Trabalho sobre Populações Indígenas, em 1982, cujo objetivo era desenvolver ações internacionais sobre os direitos destas populações. Dentre muitas ações, a principal delas resultou na aprovação da Declaração sobre Direitos dos Povos Indígenas, em setembro de 2007, por ocasião da Assembleia Geral da ONU, em Nova Iorque (ONU, 2007).

$\mathrm{Na}$ referida Declaração, alguns direitos são considerados elementares a todo e qualquer projeto de educação escolar indígena. Um primeiro diz respeito à autodeterminação, assegurando a todos os povos indígenas a livre determinação de seu status político e o desenvolvimento econômico, social e cultural. Isso implica em uma notável autonomia para organizar processos de educação escolar, desde a definição de currículo até os espaços físicos apropriados às necessidades mais específicas da comunidade.

O segundo refere-se ao direito ao consentimento livre, prévio e informado. Significa que os povos indígenas têm o direito de serem ouvidos antes da adoção de medidas legislativas ou administrativas de qualquer iniciativa, o que inclui, por exemplo, obras de infraestrutura, mineração, demarcação de terras e recursos hídricos.

O terceiro é o direito a reparação pelo furto de suas propriedades. Isso implica, na maioria dos casos, na reparação por danos causados a toda e qualquer propriedade indígena, seja ela cultural, espiritual, intelectual ou religiosa subtraída sem o consentimento prévio do povo expropriado, operação realizada, geralmente, pelos próprios Estados nacionais. Para o indígena, todo dano causado contra seu povo constitui uma violação à tradição e contraria os ensinamentos dos ancestrais.

$\mathrm{O}$ quarto direito refere-se à manutenção de suas culturas, o que implica desde a preservação de nomes tradicionais das pessoas e lugares perpassando as distintas esferas sociais, como a política, jurídica e administrativa, inclusive, nos processos de tradução. Inclui-se aí a manutenção das tradições espirituais, aspecto que atua como que uma amálgama entre as distintas dimensões da vida coletiva.

Por fim, um quinto direito refere-se à comunicação, ou seja, o direito de as populações indígenas manterem os seus próprios meios de comunicação em suas línguas originárias, sendo assegurado, também, o acesso aos meios de comunicação

«Toda esta controvérsia e a consequente interpretação surgiram e se difundiram por causa dos bárbaros do Novo Mundo, chamados popularmente de índios que, desconhecidos antes em nosso mundo, caíram há quarenta anos em poder dos espanhóis» (VITÓRIA, 2006: 37, grifos nossos). 
não-indígenas, de modo que a mídia pública contribua com a reflexão em torno do valor da diversidade cultural indígena (ONU, 2007).

Com base nestes direitos, a educação escolar indígena vem deixando de ser, de forma gradativa, um instrumento de colonialidade, ou seja, de tratamento do indígena enquanto subalterno, inculto e incapaz, para transformar-se em um espaço de luta, resistência e valorização do conjunto de elementos e saberes culturais. Desde a perspectiva dos indígenas Potiguaras 8 , situados no estado da Paraíba,

A educação diferenciada ou educação escolar indígena é uma das bandeiras de luta da etnia Potiguara, pois acreditam que a escola desempenha um papel essencial na formação das novas gerações. Exigem uma política mais definida para a educação indígena, com respeito a construção de um currículo ou proposta pedagógica que considere os aspectos do bilinguismo, do interculturalismo, da religiosidade e tradições da etnia (Nascimento, 2012: 17).

O reconhecimento e respeito aos princípios filosóficos que regem a vida dos diferentes grupos étnicos indígenas é uma alternativa que favorece a revisão das próprias concepções e perspectivas educacionais hegemônicas que estão cada vez mais alinhadas aos interesses do capital, provocando uma crescente reificação do humano e destruição da biodiversidade.

De modo a assegurar os direitos contidos na Declaração sobre Direitos dos Povos Indígenas, em 1998, foram definidos pelo Ministério da Educação, os princípios da educação escolar indígena, organizados sob a forma de Diretrizes Curriculares Nacionais (DCN) para a Educação Escolar Indígena na Educação Básica (Brasil, 20I2). O documento assegura a participação indígena na elaboração de projetos de escola, escolha da área e o modelo de organização e gestão; desenvolvimento de currículos específicos; organização de calendários escolares que respeitem as memórias históricas, as identidades étnicas, as línguas e ciências produzidos por cada grupo; criação e uso de metodologias de ensino diferenciadas; incorporação de processos próprios de aprendizagem; implementação de programas escolares e processos de avaliação da aprendizagem; viabilização de cursos de formação dos professores indígenas; e produção de materiais didáticos em línguas indígenas e em português (Brasil, 1998).

Segundo esses princípios, a escola indígena deve ser específica e diferenciada, e os próprios indígenas seus agentes e coautores. Significa que a escola deve assumir um caráter intercultural, valorizar a língua materna e o bilinguismo, abarcar a globalidade do processo de aprendizagem, elaborar o currículo com conhecimentos indígenas articulados às ciências e demais perspectivas filosóficas e culturais. Isso porque o currículo não se reduz a um conjunto de disciplinas ou uma lista de conteúdos, mas engloba a vida do aluno e objetiva a formação integral do ser humano, articulando vivências, conhecimentos e diálogos interculturais e intergeracionais.

A Lei de Diretrizes e Bases da Educação Nacional (LDBEN, 1996), através dos artigos 78 e 79, estabelece que cabe a União, em colaboração com os estados e municípios, assegurar a oferta de educação escolar bilíngue e intercultural nas escolas indígenas.

\footnotetext{
8 O grupo indígena dos Potiguara pertencem a etnia Tupi, ramo que possui uma média de Io.00o pessoas, localizadas no litoral norte paraibano e constituídas pelos municípios de Baía da Traição com I2 aldeias, Marcação com II aldeias e Rio Tinto com 3, numa área de aproximadamente 33.757 hectares (SILVA \& LeITE, 20I8).
} 
Por isso, a observação dos princípios desta modalidade de ensino, tanto na criação quanto na manutenção das escolas, é determinante. Neste sentido, as DCN apresentam, no art. 2. ${ }^{\circ}$, um conjunto de objetivos da Educação Escolar Indígena, os quais podem ser sintetizados em orientações aos sistemas educacionais do país, elaboração de instrumentos normativos, garantia do bilinguismo, multilinguismo e interculturalidade, gestão das escolas indígenas, regime de colaboração entre a União, Estados e Municípios e o zelo pela oferta da educação escolar indígena que respeite as lógicas, cosmovisões e o bem viver dos povos indígenas (Brasil, 20I2).

Embora possamos considerar que estes objetivos representem um significativo avanço na oferta desta modalidade educativa, na prática, há uma série de questões que dificultam a garantia das condições básicas de funcionamento da escola indígena. Para isso, faz-se necessário considerar aspectos mais amplos do contexto e presença indígena nas distintas regiões do país.

O Censo Demográfico de 2010 apontou que, das 896.000 pessoas que se declararam ou se consideravam indígenas, 572.000 (63,8\%) viviam na área rural e, destes, $517.000(57,5 \%)$ residiam em Terras Indígenas oficialmente reconhecidas (Brasil, 20I0). É evidente que há um maior percentual de indígenas vivendo em áreas rurais que em áreas urbanas, bem como em terras demarcadas. $O$ total de $84,4 \%$ da população não indígena vive nos centros urbanos, enquanto que a indígena é de apenas $36,2 \%$, o que denota o forte vínculo dos povos autóctones com a terra e a floresta. Informações publicadas pelo Ministério da Educação (MEC), que tem por base o Censo Escolar de 20I8, indica que 3.288 escolas indígenas estão localizadas em área rural e 57 escolas em área urbana (Brasil, 20I8). Considerando que as formas de subsistência dos indígenas dependem da natureza e da produção em pequenas propriedades, é possível deduzir que as comunidades e escolas indígenas situadas em áreas urbanas sofrem algum tipo de necessidade.

O crescente processo de urbanização das últimas décadas, associado as dificuldades de subsistência na zona rural, especialmente dos grupos que estão sem demarcação de seus territórios tradicionais, tem levado muitos indígenas a viverem na mendicância, convivendo com doenças, fome, desnutrição, além do preconceito histórico que sustenta sua condição de subalternidade. Não por acaso, segundo dados do Centro de Estudos das Relações de Trabalho e Desigualdades', os grupos indígenas configuram entre os mais pobres da América Latina. E essa condição de pobreza afeta qualquer projeto de educação e o desenvolvimento da aprendizagem, pois, como constatado por Sawaya (2006), ninguém aprende sem condições nutricionais mínimas.

De acordo com dados da Secretaria de Educação Continuada, Alfabetização, Diversidade e Inclusão (SECADI), vinculada ao MEC, o Brasil possui 305 povos e 274 línguas. O Censo Escolar de 2018 apontou a existência de 3.345 escolas indígenas de educação básica no país, 255.888 matrículas de alunos e 22.590 professores (Brasil, 2018). Só o estado do Amazonas, por exemplo, que tem mais de 120.000 indígenas distribuídos em 72 etnias e 62 municípios, possui uma média de 50.000 alunos regularmente matriculados nas redes estadual e municipais de educação escolar indígena (Amazonas, 2019).

Mas, como essas escolas se organizam no contexto dos territórios indígenas? $\mathrm{O}$ que as diferencia da escola não indígena? Quais são os principais desafios?

9 Para maiores informações, consultar https://ceert.org.br/. 


\section{I. Organização física e pedagógica das escolas indígenas}

A organização da escola indígena possui duas grandes dimensões, a física e a pedagógica. Ambas se complementam e nesta relação é que os diferenciais aparecem como especificadores de sua singularidade. A começar pela escolha dos locais de edificação que, em consonância com a legislação desta modalidade de ensino, devem ocorrer em comum acordo com a comunidade indígena que usufruirá da estrutura, observando requisitos mínimos relacionados à instalação de energia elétrica, acesso a água potável, acessibilidade para deficientes físicos, instalação de internet, esgoto sanitário, etc. Os espaços físicos da escola devem favorecer o trabalho pedagógico, por isso são planejados para a realização de atividades culturais próprias, atendimento à educação infantil (quando for o caso), bibliotecas com acervo variado, áreas de lazer e esporte, espaço para a confecção de artesanatos e outros utensílios próprios, espaço para laboratórios de informática, ciências e línguas, alimentação escolhida pela comunidade e adequada às etnias (Santa Catarina, 2018).

$\mathrm{Na}$ prática, há uma série de dificuldades e contradições no atendimento dessas demandas de infraestrutura física e pedagógica. O Censo Escolar de 2015, do MEc, apontou que somente $53,5 \%$ das escolas indígenas do país possuem material didático específico para o grupo étnico, ou seja, para metade das escolas não está disponível (Brasil, 20I5). Diante disso, algumas escolas chegam a utilizar material de outra etnia, uma afronta aos direitos de ter uma educação escolar indígena bilíngue, o que inclui a língua materna, princípio indispensável à alfabetização. Quando se trata de laboratórios de informática, ciências e linguagens, a situação é mais complexa, pois demanda maior investimento e atenção do poder público. Este, por sua vez, tem sido moroso e, por vezes, omisso para assegurar as condições mínimas de funcionamento das escolas indígenas. De acordo com o Censo Escolar de 20I8, somente 6,84\% das escolas indígenas possuem laboratório de informática, $0,50 \%$ tem laboratório de ciências, 8,oi\% possuem bibliotecas e I4,73 contam com acesso à internet. Além do mais, I.970 escolas não possuem água filtrada, I.076 não possuem energia elétrica e I.634 escolas não possuem esgoto sanitário instalado (Brasil, 20I8) - um reflexo do descaso dos sistemas de ensino à educação indígena.

Quanto a construção das escolas indígenas, vigora o regime de colaboração entre os entes federados. Para a manutenção das escolas indígenas que possuem ensino fundamental, a União repassa recursos através do Programa Dinheiro Direto na Escola (PDDE-Campo), criado em I995. O objetivo é repassar recursos de acordo com o número de alunos matriculados, a fim de que cada unidade escolar possa administrar a manutenção e fazer pequenos investimentos na escola. Cada escola é responsável pelo recebimento, execução e prestação de contas (Santa Catarina, 20ı8). Mesmo assim, a manutenção das condições mínimas de dignidade e funcionalidade da escola indígena necessita ser debatido, ou melhor, priorizado, pois não está atendendo as expectativas e necessidades. Dizemos isso, pois os dados elucidam o desprezo que essas escolas ainda sofrem por parte de governantes e de gestores educacionais.

Quanto à construção de escolas indígenas, o desenho arquitetônico pode variar devido às condições do clima e da decisão consensuada entre a gestão educacional e a comunidade indígena. Esta opção se justifica porque a arquitetura da escola favorece a realização de práticas culturais enquanto elementos formativos, além da dimensão estética evocar aspectos da cosmovisão e espiritualidade da comunidade em questão. 
Em todos os níveis e dimensões da educação escolar indígena, o sistema de ensino tem o dever de assegurar as condições de funcionalidade, o que inclui a maior presença possível de professores e gestores da respectiva comunidade indígena. É uma forma de asseverar que os saberes e práticas tradicionais ancoram o acesso e o diálogo com outros conhecimentos, privilegiando modos próprios de conhecer, investigar e sistematizar o conhecimento de cada etnia, valorizando a oralidade, a cultura, a história da comunidade e a relação com a terra, considerada pelas populações indígenas uma entidade viva (Brasil, 20I2).

Com o aumento de licenciaturas indígenas no país, houve também uma maior ocupação dos espaços de docência nestas escolas por parte de professores da própria comunidade indígena. Ao traçar um comparativo entre os dados do Censo Escolar de 2015 e 20I8, verificamos um aumento de 20.238 para 22.590 no número de professores que atuam nestas escolas, independentemente de serem indígenas ou não. $\mathrm{Na}$ educação infantil e nos anos iniciais do ensino fundamental, geralmente há um único professor(a) como docente, tal como ocorre nas escolas não indígenas. Já nos anos finais do ensino fundamental e ensino médio, a organização é disciplinar, no entanto, são crescentes as experiências de integração curricular por área de conhecimento, numa perspectiva interdisciplinar.

Desde 20I5, a licenciatura intercultural indígena possui Diretrizes Curriculares Nacionais (Brasil, 20I5) que definem objetivos de formação de professores para atuar nas escolas indígenas. $\mathrm{O}$ ingresso dos professores indígenas nos quadros do magistério das redes públicas de ensino ocorre por meio de concursos ou processos seletivos públicos. Assim, passam a usufruir do plano de carreira docente com progressão funcional e a possibilidade de aperfeiçoamento profissional.

A formação específica de professores é indispensável tanto à docência quanto à gestão da escola indígena, pois uma das metas é o empoderamento dos próprios indígenas para organizarem e realizarem a gestão de suas escolas, com participação ativa da comunidade. O Censo Escolar de 2015 apontou a existência de apenas 20 instituições de ensino superior públicas que, até aquele ano, haviam habilitado I.96I professores indígenas (Brasil, 20I5). O fato de muitas regiões do país não possuírem oferta de formação, em nível de graduação, para integrantes das comunidades indígenas, faz com que muitos dos professores não-indígenas atuem nestas escolas. Esse fato tem exigido sensibilidade dos professores para uma mútua aprendizagem e, ao mesmo tempo, atenção para que a escola não reproduza a colonialidade do saber, estratégia que desconsidera o conjunto de conhecimentos e experiências indígenas, enquanto elementos de aprendizagem e desenvolvimento humano, cultural, científico e tecnológico.

É por este motivo que a organização do Projeto Político-Pedagógico (PPP) das escolas indígenas deve ser resultado da expressão da autonomia, identidade e da cultura de cada etnia indígena. Deve estar em consonância com os princípios e objetivos da educação escolar indígena nacional, bem como com as aspirações das comunidades locais. Assim, o PPP precisa amparar-senos princípios da interculturalidade, bilinguismo e multilinguismo, além de considerar as especificidades da organização coletiva e da territorialidade.

A perspectiva da interculturalidade presente nos fundamentos da educação escolar indígena se opõe às noções de integracionismo. Significa que esse processo de escolarização não visa preparar as crianças e os jovens indígenas para abandonar suas raízes 
e viver na sociedade não indígena. Visa, acima de tudo, assegurar a sociodiversidade indígena, promover os direitos de aprendizagem e fortalecer as identidades culturais (Brasil, 20I2).

A proposta pedagógica tem de considerar que a educação escolar indígena possui uma sistemática específica. $\mathrm{O}$ processo pedagógico tem de reconhecer as formas de construção do conhecimento dos próprios indígenas, possibilitando interação e diálogo com outros conhecimentos sistematizados pela escola não indígena. Essa dinâmica potencializa o espaço da oralidade e pressupõe o uso da escrita, de modo que ocorra o processo reflexivo e a apropriação conceitual do conhecimento veiculado no cotidiano escolar, enquanto um instrumento de compreensão do contexto sociocultural da comunidade indígena e seu entorno (Brasil, 20I2).

Associada ao PPP e as condições físicas e pedagógicas da escola indígena, está a dimensão curricular. O currículo orienta-se pelas concepções e práticas definidoras da função sociocultural da escola indígena, o que inclui a organização temporal e espacial, o desenvolvimento do trabalho pedagógico, o conjunto de relações intrínsecos ao processo escolar, as relações do ambiente escolar com a sociedade, as relações de poder na atividade educativa e as concepções em torno da construção do conhecimento escolar.

A proposta curricular da escola indígena é uma elaboração coletiva e contempla os valores e interesses etnopolíticos das comunidades. De acordo com as DCN, além de flexíveis e adaptados ao contexto da comunidade indígena, os currículos devem considerar as condições de escolarização dos alunos e as questões estruturais e organizacionais do processo de ensino-aprendizagem. Além do mais, «devem ser ancorados em materiais didáticos específicos, escritos na língua portuguesa, nas línguas indígenas e bilíngues, que reflitam a perspectiva intercultural da educação diferenciada, elaborados pelos professores indígenas e seus alunos e publicados pelos respectivos sistemas de ensino» (Brasil, 2012: art. I5).

O currículo das escolas indígenas possui variações, pois cada escola é autônoma para definir a sua matriz curricular. Significa que há liberdade para elaboração de diferentes desenhos curriculares e espaço para a inclusão de diferentes componentes curriculares, além daqueles que compõem a base nacional comum. O diferencial das escolas indígenas está na possibilidade de oferta de novos componentes curriculares de interesse da comunidade, mas especialmente nas formas próprias e diversas de abordar e produzir conhecimento das diferentes ciências e culturas, articulado ao contexto de cada etnia.

As escolas dos indígenas Potiguara, da Paraíba, por exemplo, possuem três componentes curriculares diferenciados: Tupi, língua falada pelos antigos habitantes das terras de Monte-Mór; Etno-história, disciplina voltada ao conhecimento da história das nações indígenas e a historicidade dos povos, que conta com a participação direta dos anciões; e Arte e cultura, na qual se aprende a confeccionar artesanatos, pinturas corporais e outras atividades que contribuem com o cultivo da cultura potiguara. É em torno destes componentes que os demais conhecimentos escolares são abordados (Silva \& Leite, 20I8).

Outro fator relevante que afeta as escolas indígenas é o transporte escolar. Há muitas comunidades indígenas situadas distantes da escola e as crianças dependem de transporte oferecido pelo Estado. Como vimos, o Censo Demográfico de zoro apontou que a maioria da população indígena vive em áreas rurais. Esse fato faz com 
que muitas crianças dependam de transporte escolar. No estado de Santa Catarina, por exemplo, o transporte escolar atende, conforme dados do Censo Escolar de 2015, 4I\% dos alunos indígenas. Das 2.596 matrículas da rede estadual, I.068 necessitam do transporte. Já no Amazonas, assim como boa parte da região amazônica, o transporte escolar é fluvial. Não raras vezes os alunos indígenas perdem o início do ano letivo devido à demora na contratação de empresas para a prestação do serviço. Esse é um dos motivos de evasão e abandono escolar na região, caracterizada por uma condição socioambiental com desafios geográficos e demográficos distintos das demais regiões do país (Amazonas, 2019).

Não podemos deixar de mencionar a questão da alimentação escolar. A preocupação com a alimentação escolar é, primeiramente, que as crianças indígenas, assim como as demais, tenham uma alimentação saudável. Ademais, o próprio Programa Nacional de Alimentação Escolar (PNAE) assegura que os cardápios devem atender às especificidades culturais de cada comunidade indígena (Brasil, 20I3).

No contexto do Amazonas, a Secretaria de Estado da Educação adquire alimentos produzidos pelas organizações indígenas e os distribui nas escolas, valorizando a agricultura familiar, o equilíbrio alimentar, os diferentes sabores e as formas de produção ambientalmente sustentáveis (Amazonas, 2019a). Em Santa Catarina, a Secretaria de Estado da Educação faz a aquisição de alimentos junto as cooperativas de agricultura familiar e os distribui às escolas por intermédio de suas coordenadorias regionais. Além disso, encaminha um valor adicional às escolas para a aquisição de alimentos perecíveis complementares (Santa Catarina, 20I8).

Ainda são muitos os desafios a serem enfrentados pelos povos indígenas no que diz respeito ao atendimento dos requisitos físicos e pedagógicos da educação escolar indígena. $\mathrm{O}$ direito à educação está associado à luta pela demarcação das terras, à preservação do meio ambiente e da biodiversidade, ao reconhecimento da diversidade cultural, ao direito à diferença e à autodeterminação. Mesmo diante de um cenário político que contrapõe o processo de ampliação da educação escolar indígena, a resistência e articulação dos povos autóctones se fortalece em defesa de seus direitos e, por consequência, do ser humano e demais seres vivos. Daí a necessidade de uma formação que empodere e emancipe os estudantes indígenas.

\section{Formação cultural-técnico-profissional e educação escolar indígena}

Toda formação que visa emancipar homens e mulheres necessita considerar o contexto da produção e reprodução da vida humana em sociedade e sua relação com a natureza. Isso porque a teia social na qual nos relacionamos não afeta apenas as condições da produção econômica e material, mas nossas subjetividades (Adorno, 20II). Pensar, portanto, a formação indígena via processo de escolarização representa um grande dilema. De um lado, incorporar e difundir escolas nos territórios indígenas representa certamente um elemento de colonialidade do saber. Mas, de outro, negar o acesso aos conceitos estruturantes da sociedade não indígena significa dificultar as possibilidades de intercâmbio, interlocução, luta e resistência. Como as escolas indígenas lidam com esta tensão?

Primeiramente, cabe salientar, que todos estamos em permanente formação, independentemente de origem, cultura e condição social. No entanto, há níveis e interesses 
distintos em jogo devido a uma série de questões inerentes a complexidade da vida social e cultural. A necessidade de compreensão da teia de relações que tecem o existir humano faz com que a educação escolar tenha sentido ao proporcionar o acesso a um conjunto de conhecimentos e experiências acumulados por uma determinada sociedade. E é aqui que a criação da escola indígena de perspectiva intercultural tem sentido, o qual será pleno se ela proporcionar o conhecimento da história da etnia em que a escola está inserida e, ao mesmo tempo, for capaz de estabelecer diálogos com outras perspectivas culturais, hermenêuticas e epistemológicas.

As diretrizes curriculares para a educação indígena sinalizam tais aberturas. Isto é, as escolas indígenas possuem autonomia para organizar as atividades escolares conforme a concepção de aprendizagem e interesse de cada comunidade. Significa que o processo de ensino-aprendizagem pode assumir variadas formas, como séries anuais, períodos semestrais, ciclos, alternância de períodos de estudo com outras atividades e em outros espaços, grupos não-seriados regidos por critérios como idade, faixa-etária, entre outros (Brasil, 20I2). É por isso que nas comunidades indígenas há distintos interesses e expectativas em relação à função da escola, geralmente associados aos possíveis intercâmbios com a sociedade não indígena.

Considerando essas premissas e, para melhor situar nossa reflexão, abordaremos separadamente as etapas da educação básica, muito embora estas sejam indissociáveis do ponto de vista da educação integral.

\section{I. Educação infantil}

A oferta de educação infantil na escola indígena é uma decisão que cabe a cada comunidade. Por este motivo, há escolas indígenas que não possuem esta etapa da educação. Mesmo assim, permanece o direito assegurado a todos os povos indígenas (Brasil, 20I2).

A criança indígena é uma criança igual a qualquer outra. O que muda, geralmente, é a forma do adulto olhá-la e concebê-la. A criança indígena se desenvolve e aprende através da convivialidade em seu contexto sociocultural. Depende de cuidados e atenção integral como as demais, aspecto que os estudos relacionados à criança indígena demonstram ser um ponto de destaque ao desenvolvimento infantil (UNICEF, 20I4).

No universo infantil indígena, a criança se educa pelo prazer de viver, não somente para sobreviver. Ela vive a sua comunidade através da interação com todos, sejam eles adultos, anciãos, adolescentes ou outras crianças. Essa participação se dá nas festividades, rituais, atividades de coleta ou produção agrícola, caça, pesca, educação e comercialização de utensílios produzidos, especialmente aqueles que vivem próximo dos centros urbanos. Acompanham o adulto e se formam na e pela convivência com eles (Melià, 1979). A criança indígena aprende pelo exemplo, através da observação, repetição e vivência fortemente marcada pela coletividade. A aprendizagem passa pelo brincar, pela imitação e escuta dos mais velhos, pelo exercício da oralidade e participação de práticas culturais e sociais próprias que ajudam a delinear as regras e valores da convivência social (Verene \& Velanga, 2008).

A educação infantil indígena é, deste modo, desafiada a não contrapor essa lógica que permeia a vida da criança na comunidade. Por isso, as escolas indígenas que optam pela educação infantil -decisão que deve ser tomada em comum acordo com 
a comunidade local-, prima pela participação direta das famílias, dos sábios e especialistas das questões tradicionais de cada etnia, em todas as fases da implementação e desenvolvimento do projeto pedagógico. Coletivamente, definem em que língua ou línguas as atividades pedagógicas serão realizadas. Essa definição possui implicações na alfabetização e na elaboração dos materiais didáticos, os quais devem incorporar aspectos socioculturais indígenas significativos e contextualizados ao universo da criança indígena.

$\mathrm{O}$ processo de ensino-aprendizagem integra atividades letivas e socioculturais desenvolvidas nos vários espaços institucionais de convivência e sociabilidade de cada etnia, como casas de cultura, casas de línguas, casas de memória, centros comunitários, assim como em outros espaços tradicionais de formação (Brasil, 20I2). Todas essas possibilidades formativas integram o PPP de cada escola, assegurando que toda criança tenha no contexto escolar a compreensão dos elementos que possam fortalecer a sua identidade indígena, favorecendo, assim, o diálogo e vivência intercultural desde a infância.

\subsection{Ensino fundamental}

Assim como no ensino regular, o ensino fundamental é uma etapa obrigatória na educação indígena. Constitui-se em um direito público subjetivo (Brasil, 20I2) que possibilita a emancipação e a libertação de amarras da colonialidade, revisitando aquilo que ainda hoje impede o reconhecimento da alteridade das populações autóctones. «Se nós, povos indígenas, até hoje estamos vivos e com nossas identidades, é porque aprendemos a usar a escola a nosso favor. A educação é para nós, para nos curar, e não para nos dominar» (Guajajara, 2019: 173).

Por isso que no contexto da formação indígena, o ensino fundamental constitui o período de afirmação da identidade dos meninos e meninas. É uma fase da vida em que passam a ter maiores responsabilidades na comunidade. Deste modo, o acesso ao conjunto de conhecimentos tradicionais, culturais e científicos mais sistematizados amplia a capacidade de compreensão e reflexão sobre o passado e a condição histórica na qual se encontram. Além de valorizar a cultura da oralidade, o ensino fundamental das escolas indígenas proporciona aprendizagens dos códigos de leitura e escrita, a apropriação de conhecimentos ligados às ciências humanas, da natureza, matemáticas e linguagens (Brasil, 20I2). É na articulação do conjunto de saberes, conhecimentos e experiências que desenvolvem as capacidades individuais e coletivas imprescindíveis ao convívio sociocultural de cada indígena na comunidade de pertença e na relação com outros grupos humanos, indígenas ou não. Aprendem a se posicionar no mundo, não como seus proprietários, mas como parte dele. Daí decorre o profundo respeito e reverência aos ancestrais, à terra e à natureza.

O ensino fundamental é propício ao desenvolvimento das habilidades artísticas, culturais e esportivas. Por isso, as propostas pedagógicas devem valorizar a corporeidade e a criação de espaços de aprendizagem e sociabilidade através de músicas, danças, pinturas, jogos, produção de artefatos culturais, dentre outras atividades que aguçam o espírito coletivo, um dos fundamentos da formação indígena. Em escolas indígenas que dispõem de acesso à internet e a tecnologias de informação e comunicação, podem ser desenvolvidos projetos e atividades com o seu uso, superando visões 
romantizadas do indígena enquanto um ser extemporâneo. Isto porque os indígenas também podem ser, como já existem casos, «advogados, médicos, enfermeiros, cineastas, músicos, políticos, guardiões da floresta, mulheres, crianças, homens, líderes, gente comum... São e podem ser, enfim, tudo o que cabe na diversidade da sociedade brasileira» (Guajajara, 2019: 17I-172).

As práticas educativas e curriculares estão associadas às práticas do cuidar nas diferentes fases da vida e é no ensino fundamental que, tanto a escola, quanto a comunidade de pertença, devem assegurar aos estudantes condições favoráveis à construção do bem viver de suas comunidades. Enquanto direito público subjetivo, o Estado, através dos entes federados, deve assegurar e promover a universalização desta etapa escolar nas comunidades indígenas, com qualidade e respeito as peculiaridades de cada etnia (Brasil, 20I2). Somente assim, as comunidades indígenas poderão ter melhores condições de enfrentar e resistir as inúmeras violências sofridas, tanto físicas quanto simbólicas, provocadas por diferentes grupos, desde religiosos fundamentalistas até os que desejam explorar as riquezas minerais existentes em suas terras.

\subsection{Ensino médio}

[...] Acreditamos em uma educação que dialogue com o movimento da vida, com o viver no território, pois o território também ensina. Consideramos o aprender por meio dos conhecimentos tradicionais como um 'aprender sem se prender', sem prender os corpos no lugar único da sala de aula, pois quando cercamos os corpos limitamos a mente (Guajajara, 2019: 172).

Há uma tendência educativa formulada pelo movimento iluminista, de nos contextos escolares/acadêmicos, elevarmos tudo a um nível de abstração e, devido a isso, classificarmos o que abstraímos como de maior relevância frente ao mundo do sensível e do corporal, resultando em dualismos entre razão-emoção, corpo-mente, natureza-sociedade.

O ensino médio indígena procura evitar esses dualismos na formação dos jovens na medida em que dá ênfase a uma educação voltada a integralidade do ser humano, ao território e a territorialidade, a sustentabilidade socioambiental e o respeito à diversidade dos estudantes. Visa aprofundar a compreensão e vivência dos valores da comunidade de pertença de modo que possam colaborar diretamente na organização da comunidade indígena nas diferentes dimensões da vida em sociedade, como as questões sociais, políticas, econômicas e culturais.

O ensino médio indígena articula no currículo conhecimentos tradicionais, culturais e científicos tendo em vista a formação para a gestão territorial autônoma, refletindo as condições e possibilidades de elaborar e desenvolver projetos sustentáveis e de produção alternativa à comunidade indígena. Há que se considerar que muitas delas sofrem com a desassistência nos processos de produção alimentícia, medicinal e cultural, inviabilizando projetos e ações inovadoras para problemas não só indígenas, mas da sociedade em geral, em especial nas áreas ambientais, da saúde e da educação (Brasil, 20I2).

A formação integral que propõe o ensino médio indígena, quando assegurado as condições indispensáveis para o desenvolvimento da aprendizagem, coloca os jovens 
em condições para atuar em áreas imprescindível às comunidades indígenas, como na saúde, docência, gestão territorial e ambiental, tecnologias da informação, dentre outras atividades (Brasil, 20I2). É crescente o ingressos de muitos jovens indígenas aos cursos de graduação e pós-graduação, devido as políticas afirmativas implementadas nas últimas décadas. A ocupação desses espaços são cruciais no processo de reconhecimento das epistemes indígenas ${ }^{10} \mathrm{e}$ de suas identidades culturais.

Mesmo em um contexto de muitas limitações, algumas possibilidades se abrem ao ensino médio indígena enquanto perspectivas de futuro, especialmente através de parcerias com entidades diversas. Neste sentido, as DCN da Educação Indígena (20I2) preveem, inclusive, a oferta de Educação Profissional e Tecnológica nos territórios etnoeducacionais, a ser oferecida de modo interinstitucional por meio de convênio com diferentes tipos de instituições (Brasil, 20I2: art. I3). Ainda que restritas e de pouco impacto social, essas parcerias fortalecem o diálogo intercultural em contextos educativos, o que possibilita a produção de novos conhecimentos científicos na elaboração de propostas, projetos e respostas aos desafios das comunidades.

\section{Considerações finais}

Embora o século XIx tenha sido marcado por processos de independência e consequente formação dos estados nacionais, estes mantiveram os povos indígenas sob certa colonialidade. Quijano (2009) explicitou que essa condição se manteve devido a sua intrínseca relação com o sistema capitalista, que opera com base na imposição e reprodução da desigualdade a partir da ideia de raça. A colonialidade, segundo o autor, além de fazer uso do preconceito racial, se mantém também através da dominação epistêmica, pois considera como válido apenas o conhecimento ocidental (desde o letramento até as metodologias de ensino), desperdiçando o conjunto de saberes dos povos autóctones, geralmente classificados como não científicos.

Superar e resistir à colonialidade é um desafio que as escolas indígenas enfrentam, pois ela está entranhada nas distintas esferas de poder e na sociedade em geral. Se torna visível na falta de prioridade à educação indígena, desde a oferta das condições básicas e dignas das estruturas físicas e pedagógicas necessárias à funcionalidade de qualquer instituição educativa, até a falta de valorização da cultura, língua, crenças e saberes indígenas.

Diante disso, consideramos que a educação escolar indígena tem obtido conquistas em algumas regiões do país, especialmente onde as gestões públicas têm levado a sério as prerrogativas legais quanto ao direito à educação que as crianças e jovens indígenas possuem, reconhecendo o direito à diferença e a autodeterminação. Esses avanços têm profunda relação com a capacidade de organização das distintas comunidades e etnias indígenas na reivindicação dos seus direitos constitucionais. A emancipação e o reconhecimento social das identidades e alteridades indígenas são intrínsecos ao processo de decolonialidade do poder e do saber. É condição para que as experiências

1o Referente a este tema, sugerimos consultar o livro Educación e interculturalidad: aproximación crítica y decolonial en contexto indígena, organizado por Segundo Quintriqueo Millán e Daniel QuilaQueo Rapimán, publicado pela Ediciones Universidad Católica de Temuco, do Chile, em 2org. Possui uma série de reflexões e relatos de experiências que afirmam uma episteme indígena, porque singular e própria dos povos autóctones latino-americanos. 
educativas indígenas possam integrar o conjunto de perspectivas formativas necessárias à uma educação intercultural.

Contudo, isso só está sendo possível onde as propostas pedagógicas, o currículo, a formação de professores e a gestão da escola possui a marca da comunidade indígena, onde há o reconhecimento da singularidade e das necessidades pedagógicas de cada escola. Estes pressupostos estão presentes nos documentos que regulam a educação indígena, mas principalmente em experiências de escolas em que o indígena é o agente principal no processo de ensino-aprendizagem, configurando aquilo que Meliá (I979) considera escola indígena «de fato» e não apenas «para» indígenas. Esta última não passa de uma mera estratégia de manutenção de certa colonialidade do poder, do saber e do ser.

Daí concluímos que a resistência e a desconfiança de muitas comunidades e etnias indígenas ao processo de escolarização decorrem da percepção de que a escola é ainda um elemento colonial de políticas assimilacionistas e integracionistas dos estados nacionais. O desafio reside em estabelecer diálogos e oferecer apoio para que as escolas indígenas possam refletir os ideais formativos de suas comunidades, de modo que os saberes, conhecimentos e experiências próprias sejam respeitados e valorizados no diálogo intercultural que tem de caracterizar e fundamentar as políticas e práticas educacionais, uma necessidade cada vez mais premente no Brasil, bem como em toda Abya Ayla, desafiadas a pensar a partir delas mesmas.

\section{Bibliografia}

Adorno, T. W. (20II). Educação e Emancipação. Trad. Wolfgang Leo Maar. São Paulo: Paz e Terra. Amazonas. Secretaria de Estado da Educação. (2OI9a). Educação escolar indígena. Recuperado em Io de setembro de 20I9, de http://www.educacao.am.gov.br/educacao-escolar-indigena/.

Amazonas. (2019b). Governo do Amazonas faz aquisição de alimentos da agricultura familiar indígena para compor merenda escolar. Recuperado em I2 de setembro de 2019 , de http://www.educacao.am.gov.br/2019/o2/governo-do-amazonas-faz-aquisicao-de-alimentos-da-agricultura-familiar-indigena-para-compor-merenda-escolar/.

ApinajÉ, J. K. R. (20I7). Processo de Educação Intercultural: possíveis reflexões. In M. B. LANDA \& A. F. HerbetTA (coords.) Educação indígena e interculturalidade: um debate epistemológico e político (pp. 74-8I). Goiânia: Editora da Imprensa Universitária.

Brasil. (1988). Constituição da República Federativa do Brasil. Brasília/DF. Recuperado em 2 de outubro de 2019, de http://www.planalto.gov.br/ccivil_03/constituicao/constituicao.htm.

Brasil. (1998). O Governo Brasileiro e a Educação Escolar Indígena. Ministério da Educação/ Secretaria de Educação Fundamental, Departamento de Política da Educação Fundamental, Coordenação Geral de Apoio às Escolas Indígenas. Brasília: MEC/SEF/DPEF/CGAEI.

Brasil. (2003). Lei n. ${ }^{\circ}$ I0.709, de 31.7.2003, que trata da responsabilidade dos estados e municípios para com o transporte escolar. Recuperado em 4 de outubro de 20I9, de http://www. planalto.gov.br/ccivil_03/leis/2003/Lio.709.htm.

Brasil. (2009). Lei n. ${ }^{\circ}$ II.947, de I6 de junho de 2009. Dispõe sobre o atendimento da alimentação escolar e do Programa Dinheiro Direto na Escola aos alunos da educação básica. Brasília/DF. Recuperado em 22 de setembro de 2019, de http://www.planalto.gov.br/ccivil_03/_Ato2007-2010/2009/Lei/Liig47.htm.

Brasil. (20Io). Censo Demográfico - Fundação Nacional do Índio. Recuperado em I3 de agosto de 2019, de http://www.funai.gov.br/arquivos/conteudo/ascom/20I3/img/ı2-Dez/pdf-brasil-ind.pdf. 
Brasil. (20I2). Resolução CNE/CEB n. ${ }^{o}$ s, de 22 de junho de 20I2. Define Diretrizes Curriculares Nacionais para a Educação Escolar Indígena na Educação Básica. Recuperado em I8 de abril de 2020, de http://www.crmariocovas.sp.gov.br/Downloads/ccs/concurso_2013/ PDFs/resol_federal_05_I2.pdf.

Brasil. (20I3). Resolução/CD/FNDE $n .^{\circ}$ 26, de I7 de junho de 20I3. Dispõe sobre o atendimento da alimentação escolar aos alunos da educação básica no âmbito do Programa Nacional de Alimentação Escolar - PNAE. Brasília/DF. Recuperado em I2 de setembro de 20I9, de https:// www.fnde.gov.br/index.php/acesso-a-informacao/institucional/legislacao/item/462o-resolu $\% \mathrm{C}_{3} \% \mathrm{~A}_{7} \% \mathrm{C}_{3} \% \mathrm{~A}_{3} \mathrm{O}-\mathrm{cd}-$ fnde-n $\% \mathrm{C}_{2} \% \mathrm{BA}-26$,-de-17-de-junho-de-2or3.

Brasil. (2OI5). Resolução CNE $n^{\circ}{ }_{\text {I }}$ de 7 de janeiro de 20I5. Institui Diretrizes Curriculares $\mathrm{Na}$ cionais para a Formação de Professores Indígenas em cursos de Educação Superior e de Ensino Médio e dá outras providências. Recuperado em I8 de abril de 2020, de http://portal.mec.gov.br/index.php?option=com_docman\&view=download\&alias=I6870-res-cnecp-00I-070I20I5\&Itemid=30192.

Brasil. (20I8). Instituto Nacional de Estudos e Pesquisas Educacionais Anísio Teixeira - Ministério da Educação. Censo Escolar 20I8. Brasília/DF. Recuperado em 25 de agosto de 2019, de http://inep.gov.br/censo-escolar.

Castro-Gómez, S. (20II). Crítica de la razón latinoamericana. Bogotá: Pontificia Universidad Javeriana.

Castro-Gómez, S. \& Grosfoguel, R. (2007). Prólogo. Giro decolonial, teoría crítica y pensamiento heterárquico. In S. Castro-Gómez \& R. Grosfoguel (coords.) El Giro Decolonial: Reflexiones para una diversidad epistémica más allá del capitalismo global. Bogotá: Siglo del Hombre Editores; Universidad Central, Instituto de Estudios Sociales Contemporáneos, Pontificia Universidad Javeriana, Instituto Pensar.

Estermann, J. (2006). Filosofía Andina: Sabiduría indígena para un mundo nuevo. 2. ${ }^{\text {ed. La }}$ Paz: ISEAT.

Ferreira, M. K. L. (1992). Da origem dos homens a conquista da escrita: um estudo sobre os povos indígenas e educação escolar no Brasil. Dissertação de Mestrado em Antropologia social. São Paulo, USP.

Fornet-Betancourt, R. (200I). Lo intercultural: el problema de su definición. In Intercultural: balance y perspectivas. Encuentro Internacional sobre Interculturalidad. Barcelona: Сіров. Recuperado em 7 de setembro de 20I9, de http://www.cidob.org/es/publicaciones/ monografias/monografias/interculturael_balance_y_perspectivas.

Freire, J. R. B. (2004). Trajetória de muitas perdas e poucos ganhos. Educação escolar. Rio de Janeiro: UERF.

Grosfoguel, R. (20I6). A estrutura do conhecimento nas universidades ocidentalizadas: racismo/sexismo epistêmico e os quatro genocídios/epistemicídios do longo século xvi. Revista Sociedade e Estado, $3 I(\mathrm{I})$, Jan./Abril.

Guajajara, S. (20I9). Educação Indígena: esperança de cura em tempos de enfermidade. In F. CÁssio (coord.) Educação contra a barbárie: por escolas democráticas e pela liberdade de ensinar (pp. 17I-174). São Paulo: Boitempo.

Krause, J. I. A. (20I9). Modernidad y conquista. El despertar de los derechos fundamentales y del derecho internacional en Francisco de Vitoria. Las Torres de Lucca, 8(15), 15-40, Jul.-Dic.

Mejía Huamán, M. (2010). Hacía una Filosofía Andina. Lima/Peru. 2. ${ }^{a}$ edición computarizada.

Mejía Huamán, M. (20ir). Teqse: la cosmovisión andina y las categorias quéchuas como fundamentos para una filosofía peruana y de América Andina. Lima/Peru: Editorial Universitaria.

Mejía Huamán, M. (20I8). Hacia una filosofía andina. Santiago de Surco/Peru: Universidad Ricardo Palma - Instituto de Investigaciones Filosóficas.

Melià, B. (1979). Educação indígena e alfabetização. São Paulo: Loyola.

Méndez, J. M. M. (2009). Educação intercultural e justiça cultural. São Leopoldo: Nova Harmonia.

Mignolo, W. (2010). Desobediencia epistémica. Buenos Aires: Ediciones del Signo. 
Mignolo, W. (2013). Historias locales/diseños globales. Madrid: Akal.

Mignolo, W. (20I7). Colonialidade: O lado mais escuro da modernidade. Revista Brasileira de Ciências Sociais, São Paulo, 32(94).

Nascimento, J. M. (coord.). (20I2). Etnoeducação potiguara: pedagogia da existência e das tradições. João Pessoa: Ideia.

onu - Organização das Nações Unidas. (2007). Declaração das Nações Unidas sobre Direitos dos Povos Indígenas. Recuperado em 8 de outubro de 2019, de https://pib.socioambiental.org/files/file/PIB_institucional/DECLARACAO_DAS_NACOES_UNIDAS_SOBRE_OS_DIREITOS_DOS_POVOS_INDIGENAS.pdf.

Palermo, Z. (2009). Conocimiento «otro» y conocimiento del otro en América Latina. Estud. - Cent. Estud. Av., Univ. Nac., 2I, 79-90.

Quijano, A. (2009). Colonialidade do Poder e Classificação Social. In B. de S. Santos \& M. de P. Meneses (coords.). Epistemologias do Sul. Coimbra: Edições Almedina S. A.

Quintriqueo Millán, S. y Quilaqueo Rapimán, D. (coords.). (20I9). Educación e interculturalidad: aproximación crítica y decolonial en contexto indígena. Temuco-Chile: Ediciones Universidad Católica de Temuco.

Santa Catarina (20I8). Política da Secretaria de Estado da Educação de Educação Escolar Indígena. Florianópolis: Secretaria de Estado da Educação.

Sawaya, S. M. (2006). Desnutrição e baixo rendimento escolar: contribuições críticas. Estudos Avançados, São Paulo, $20(58)$, dez.

Silva, S. F. da. \& Leite, C. M. C. (2018). Etnogeografia Potiguara da Paraíba: reflexões sobre o ensino de Geografia em escolas indígenas. Revista OKARA: Geografia em debate, I2(I), 80-IOI.

unicef. (20I4). Fundo das Nações Unidas para a Infância. Recuperado em 2I de outubro de 20I9, de https://www.unicef.org/brazil/.

Verene, M. R. y Velanga, C. T. (2008). A criança indígena e a educação infantil: as complexas relações entre a cultura e a escola na cidade. Revista Tellus, ano 8, I5, I75-191, jul./dez. Campo Grande/Ms.

VITORIA, F. de (2006 [1539]). Os indios e o direito da guerra: de indis et de jure belli relectiones. Ijuí: Unijuí.

Walsh, C. (20I3). Lo pedagógico y lo decolonial: Entretejiendo caminos. In C. WALSH (ed.) Pedagogías decoloniales: Prácticas insurgentes de resistir, (re)existir y (re)vivir. Quito: Ediciones Abya-Yala.

Walsh, C. (20I4). Pedagogías decoloniales caminando y preguntando. Notas a Paulo Freire desde Abya Yala. Revista Entramados - Educación y Sociedad, I, I7-3I. 
